\title{
Feria del Cerrado, Goiânia: la participación social para el desarollo local
}

\author{
Feira do Cerrado, Goiânia: a participação social em vista do desenvolvimento local
}

Feria do Cerrado, Goiânia: social participation in local development of view

Feria do Cerrado, Goiânia: participation sociale dans le développement local de vue

\author{
Raquel Lage Tuma* \\ Heitor Romero Marques** \\ Maria Elisabeth Alves Mesquita Soares*
}

Recebido em 27/08/2016; revisado e aprovado em 01/02/2017; aceito em 01/02/2017

DOI: http://dx.doi.org/10.20435/1984-042X-2016-v.18-n.1(15)

Resumen: En esta investigación, se tuvo como propósito el análisis de la 'Feria del Cerrado' (Feira do Cerrado), como un instrumento de desarrollo local con la participación social de los artesanos. El objetivo ha sido indicar como una feria de artesanía puede contribuir para el desarrollo local, por medio de un grupo de artesanos. El procedimiento metodológico fue la investigación exploratoria, con revisión bibliográfica, en las áreas de desarrollo local sustentable, participación social y un estudio de caso sobre la 'Feria del Cerrado' (Feira do Cerrado), una feria de artesanías, situada en el municipio de Goiânia, Brasil. Se utilizó la técnica del estudio descriptivo e investigación de campo con entrevista semi estructurada aplicada a los dirigentes y feriantes, así como la observación de la feria y conversas informales con los feriantes, con la intención de identificar la situación real y proceder a un análisis de cómo ha sido la relación entre dirigentes y feriantes. A continuación es dado el enfoque a las actividades de artesanías y el objeto de estudio de la 'Feria del Cerrado' (Feira do Cerrado), con la expectativa de que el desarrollo local sea facilitador de mejoría de la calidad de vida de grupos específicos.

Palabras clave: participación social; desarrollo local; Feria del Cerrado.

Resumo: Nesta pesquisa, se teve como propósito a analisar a Feira do Cerrado, como instrumento de desenvolvimento local, com a participação social dos artesãos. O objetivo foi indicar como a feira de artesanato pode contribuir para o desenvolvimento local, por meio de um grupo de artesãos. O procedimento metodológico foi a pesquisa exploratória, com revisão bibliográfica, nas áreas de desenvolvimento sustentável, participação social em um estudo de caso sobre a Feira do Cerrado, uma feira de artesanatos, situada no município de Goiânia, no Brasil. Utilizou-se a técnica de estudo descritivo e pesquisa de campo, com entrevista semi estruturada, aplicada aos dirigentes e feirantes assim como observação da feira e conversas com os feirantes, com a intenção de identificar a situação real e proceder uma análise de como tem sido a relação entre dirigentes e feirantes. Em seguida é dado um enfoque sobre as atividades de artesanato e sobre a Feira do Cerrado, com a expectativa de que o desenvolvimento local seja facilitador de melhoria da qualidade de vida de grupos específicos.

Palavras-chave: participação social; desenvolvimento local; Feira do Cerrado.

Abstract: This research, aimed to analyze the 'Cerrado Fair' as a local development instrument with social participation of artisans. The purpose was to indicate how and whether a craft fair can contribute to local development through a group of artisans. The methodological procedure was the exploratory research with a literature review in the areas of sustainable local development and social participation; and a case study about the 'Cerrado Fair', a craft fair, located in Goiânia, Brazil. It was used the technique of descriptive study and field research with semi-structured interviews applied to managers and fairground, as well as the observation of the fair and informal conversations with this fairground in order to identify the actual situation and make an analysis of how has been the relationship between leaders and fairground. And then is given the focus on the craft activities and the 'Cerrado Fair' object of study, with the expectation that local development is facilitating the improvement of the quality of life of specific groups.

Key words: social participation; local development; 'Cerrado Fair'.

\footnotetext{
* Universidade Estadual do Oeste do Paraná, Francisco Beltrão, Paraná, Brasil.

** Universidade Católica Dom Bosco, Campo Grande, Mato Grosso do Sul, Brasil.
} 
Résumé: Cette recherche a analysé le « Marché du Cerrado » comme outil de développement local avec la participation sociale des artisans. L'objectif était d'indiquer si et comment un marché d'artisanat peut contribuer au développement local, à travers un groupe d'artisans. La procédure méthodologique a été la recherche exploratoire, avec révision bibliographique, dans les domaines du développement local durable et de la participation sociale; et une étude de cas sur le «Marché du Cerrado ", un marché d'artisanat dans la ville de Goiânia, Brésil. Nous utilisons la technique de l'étude descriptive et de la recherche sur le terrain avec des entretiens semi-structurés appliquées aux dirigeants et marchands, ainsi que l'observation et les conversations informelles avec les marchands afin de comprendre la situation réelle. D'après les résultats nous concluons que le «Marché du Cerrado » est un facilitateur de l'amélioration de la qualité de vie des groupes spécifiques avec le développement local.

Mots-clés: participacion sociale; developpement local; Marché du « Cerrado ».

\section{INTRODUCCIÓN}

En los días actuales, se habla mucho en desarrollo local, existen diversidad en términos conceptuales y muchas veces la teoría no condice con la práctica. En este trabajo se pretende analizar si una feria de artesanías puede ser una de las herramientas de contribución para el desarrollo local de determinada localidad o para un grupo específico. Para eso, en primer momento será hecho la contextualización sobre las teorías y los conceptos sobre el desarrollo local, desarrollo sustentable, desarrollo local integrado y sustentable, así como la participación social, actividades de artesanías $\mathrm{y}$, posteriormente, un análisis de la 'Feria del Cerrado' (Feira do Cerrado), que ocurre en el municipio de Goiânia, en el Estado de Goiás, Brasil.

La investigación retratada en este trabajo se caracterizó como siendo exploratoria y de revisión bibliográfica sobre el desarrollo local, participación social y capital social en un estudio de caso sobre la 'Feria del Cerrado' (Feira do Cerrado), una feria de artesanías, en el municipio de Goiânia, Estado de Goiás, Brasil. Se utilizó la técnica del estudio con entrevistas semi estructurada aplicada a los dirigentes y feriantes, así como la observación de la feria y conversas informales con los feriantes con la intención de identificar la real situación y proceder un análisis de cómo ha sido la relación entre dirigentes y feriantes.
Como dicho arriba, las entrevistas semi estructuradas permitieron una serie de diálogos con los feriantes siempre con la preocupación de conocer cuestiones racionadas a la historia da la 'Feria del Cerrado' (Feira do Cerrado), sus dificultades en realizar las actividades, la participación y ayuda del poder público bien como una u otra particularidad que se revelase importante, como se puede ver distribuidos en los apartados dese trabajo. Además, en ese tipo de entrevistas se plantea conocer las representaciones sociales [mapas mentales] de las personas y no exactamente reproducir sus hablas textualmente. Como se puede notar la opción metodológica fue parafrasear de manera hermenéutica los pensamientos contextualizados en aquel espacio geográfico.

La 'Feria del Cerrado' (Feira do Cerrado), tiene el objetivo de divulgar y comercializar los productos de los artesanos locales, producidos en diversos ramos, tales como: alimentación, escultura en madera, cuadros artesanales en papel y pinturas, cosméticos, artículos en tejidos, cajas, biscuits, entre otros. Todos los domingos es realizada de las 9 a las 13 horas, en el 'Parque del Niño' (Parque da Criança), detrás del 'Estadio Sierra Dorada' (Estádio Serra Dourada). Una feria, cómo esta, fortalece la cultura y la tradición de la ciudad, ofrece recreación a la comunidad, además de proporcionar beneficios a la economía formal por medio de la inclusión social de los artesanos. 
Para discutirse a respecto del desarrollo local, se hace necesario evaluar otros aspectos, además del económico, social, espacial, cultural, étnico, tecnológico y político.

\section{ENTENDER EL DESARROLLO LOCAL}

Para el estudio del término desarrollo local, serán hechas algunas contextualizaciones sobre los conceptos por diversos autores. Primeramente se hará inicio al analizarse el termo desarrollo. En éste momento, no se debe pensar solamente en la cuestión económica, considerándose que se puede estudiar el desarrollo por una serie de aspectos. Del punto de vista de Souza (1999, p. 18) el término desarrollo debe designar "un proceso de superación de problemas sociales, en cuyo ámbito una sociedad se convierte, para sus miembros, más justa y legítima."

Se sabe que en la actualidad hay un esfuerzo gigantesco para la concepción e implementación de una nueva orden económica mundial a favor de la globalización, en la búsqueda de una forma de bloques más o menos regionalizados. Aunque, Buarque (2008), destaca que hay una paradoja a esa dinámica, dado que en ninguna otra época fueron tan fuertes los esfuerzos para comprender y estimular el desarrollo local, mediante la descentralización económica, social y política, cuyos resultados denotan movimientos localizados, con predominancia de las fuerzas endógenas.

En la misma óptica, anteriormente mencionada, Souza (1999, p. 18) considera la cuestión del desarrollo como siendo más amplio, entendiendo como desarrollo socio espacial, que comprende:

[...] un proceso de superación de problemas y conquistas de condiciones (culturales, técnicos tecnológicas, político institucionales, espacio- territoriales) propiciadoras de mayor felicidad individual y colectiva, el desarrollo exige la consideración simultánea de diversas dimensiones constituyentes de las relaciones sociales (cultura, economía, política) y, además, del espacio natural y social.

Siendo así, en el momento en que se piensa en desarrollo local, se debe ecualizar algunos factores y colocarlos como objetivos, tales como: la identidad cultural, la generación de actividades productivas y de renta, el desarrollo participativo, las líneas generales, es preciso distinguir la preservación, de la conservación, para decidirse sobre la utilización del espacio con la presencia de las personas.

Sobre los principios rectores para el desarrollo local, Sachs (1986) apud Frega, Lemos e Souza (2007, p. 40) señala seis aspectos:

(1) la satisfacción de las necesidades básicas; (2) la solidaridad con las generaciones futuras, en la que tanto la preservación ambiental como la viabilidad de existencia de las comunidades locales, deben tener en cuenta; (3) la participación de las poblaciones afectadas, conectando el poder público, los grupos y los individuos; (4) la preservación de los recursos naturales y del medio ambiente en general; (5) la elaboración de un nuevo sistema social, generando comprometimiento con los principios; (6) la ejecución de programas de educación.

$\mathrm{Al}$ analizar esos seis puntos rectores, individualmente, debe considerarse que la satisfacción de las necesidades básicas hace parte no solo de la obligatoriedad en tener algo para comer y un local para dormir, sino también todas aquellas indispensables para tenerse una vida digna, salud y educación. En lo que 
se refiere a la solidaridad con las generaciones futuras, se debe evaluar que la existencia de comunidades locales debe ser preservada así como el medio ambiente, a la larga, es una identidad cultural de aquella localidad.

Sobre la participación de las poblaciones afectadas, siempre se debe advertir que es necesario que tengan una importante implicación de los actores para que las políticas y mejoras que serán implementadas sean efectivamente de acuerdo con el deseado por todos. La afirmación de Buarque (2008, p. 25) de que « el desarrollo local puede ser económico y la mejora de la calidad de vida de la población en pequeñas unidades territoriales y agrupamientos humanos ».

Al travesar la problemática de la preservación de los recursos naturales y del medio ambiente todos los esfuerzos son válidos. Es necesario, entretanto, ponderar lo que es realmente objeto de preservación, no solo teniendo como parámetro el presente, pero la supervivencia de las generaciones futuras porque, el principio basilar del desarrollo local, presupone la inserción de la persona humana en el centro de todas las demás preocupaciones, en una especie de ecología humana. Para eso, en la elaboración de un nuevo sistema social es preciso voluntad política y significativas mudanzas para que se tenga un comprometimiento real con principios necesarios para la manutención de la vida. Seguramente, esa preocupación pasa por la cuestión educacional, como medio de reflexión y acción a favor de la vida.

Almeida y Blos (2000, p. 77) considera el desarrollo local como "un desarrollo desde la base, auto centrado y endógeno. No solo auto centrado, porque el enfoque no tiene obligatoriamente énfasis comunitario; no solo endógeno, porque contempla la utilización de recursos externos a la comunidad."

Como factores de desarrollo local, incluyendo la sustentabilidad, algunas preocupaciones/orientaciones deben estar presentes, tales como:

1. Manutención de la identidad cultural de los lugares;

2. Construcción de una vía democrática para el desarrollo de las localidades, con la participación activa de la población en la conducción de ese proceso;

3. Establecimiento de pequeñas escalas de operación y bajos efectos impactantes de las inversiones locales y ninguna trasformación adicional de estos espacios, lo que estaría subordinado a los parámetros de la conservación del medio ambiente y de la "rusticidad local", en un proceso de valoración sin trasformación de los elementos naturales del paisaje y de los rasgos culturales de las poblaciones nativas (BENEVIDES, 1999).

4. Movilización e identidad de las poblaciones locales y contribución para elevar las oportunidades sociales y la viabilidad y competitividad de la economía local, al tiempo en que se debe asegurar la conservación/ preservación de los recursos naturales locales (BUARQUE, 2008).

Villareal (2012) al analizar la cuestión del desarrollo local apunta perspectivas generales, en que visualiza esa modalidad de desarrollo como alternativa económica, asociada al desarrollo de la economía local o regional, a partir del incremento de la productividad del sistema productivo territorial y su inserción en el mercado global.

Otro aspecto se refiere a la política social que destaca la perspectiva colectiva. En igual sentido, la corriente de la economía social defiende la organización de la actividad económica, enfatizando la capacidad para crear relaciones comunitarias de mayor alcance y sustentarse por su participación competitiva en el mercado.

Al mismo tiempo, en que se discute sobre el tema del desarrollo local también se hace necesario abordar el concepto sobre desarrollo sustentable, ya que son dos conceptos muy próximos y, en una línea de pensamientos similares, visto que abordan la importancia de la 
identidad y de los valores culturales, la preocupación con las generaciones futuras tanto en sus aspectos ambientales como sociales, así como la cuestión de la efectiva participación de la población involucrada.

Uno de los criterios para considerar el desarrollo como sustentable, es el alcance de los objetivos propuestos en relación a no deterioración de los recursos naturales y culturales, como forma de mantenimiento de la vida en todas sus formas y extensiones. Para Irving (2002, p. 35) la concepción de desarrollo sustentable está relacionada a la "[...] ética de democratización de oportunidad y justicia, percepción de las diferencias como elemento rector de planificación, comprensión de la dinámica de códigos y valores culturales."

En otros criterios, la expresión sustentabilidad del desarrollo no significa un ajustamiento suplementar a la racionalidad del desarrollo moderno. En el núcleo del concepto - principio ético de la solidaridad - guarda inmenso desafío de asegurar la sustentabilidad de la humanidad en el planeta, en el interior de una crisis de múltiples dimensiones interdependientes e interpenetradoras: ecológicas, social, política, humana, étnica, ética, moral, religiosa, afectiva, mitológica. La sustentabilidad es un problema complejo, porque su exigencia está incorporada en tejido de problemas inseparables, exigiendo una reforma epistemológica de la propia noción de desarrollo (MORIN, 2010).

Añadiendo la calificación como integrada, hay el concepto de Desarrollo Local Integrado y Sustentable (DLIS), mientras:

[...] un proceso de promoción del desarrollo por medio de aparcería entre Estado y Sociedad, en el que ocurren acciones multisectoriales integradas, convergentes en una localidad, según una metodología que prevé, al menos: capacitación para la gestión; diagnóstico y planificación participativos; articulaciones de la oferta pública de programas con la demanda social de la localidad; monitoriamente y evaluación; fomento al espíritu emprendedor y creación de una nueva institucionalidad participativa. (CORRÊA, 2000 apud BRITO; CARON; NASCIMENTO, 2005, p. 26).

Denótese que Brito, Caron y Nascimento (2005, p. 260) indican que el DLIS tiene como nuevo enfoque "una mayor preocupación con la distribución de la renta, la sustentabilidad ambiental, la mejoría de la calidad de vida de la población, la mejora de las relaciones del trabajo, bien como la satisfacción de las necesidades básicas.

En este sentido, hay consenso en su semántica conceptual sobre desarrollo, cuyo énfasis es la constante preocupación con la mejora de la calidad de vida de la población. De esa forma, el desarrollo más equilibrado territorialmente, como descentralización política y gestión democrática local, debe hacer con que tenga iniciativa de desarrollo local de articulación del tejido productivo y de generación de trabajo y renta para enfrentar la pobreza y la segregación social.

El equilibrio conceptual no basta por sí solo en términos de desarrollo, es preciso que exista la correspondiente práctica, especialmente en relación a la planificación visando la participación social. Desde el punto de vista de Sampaio (2002) la planificación debe ser un proceso con visión de largo plazo, legitimándose por una participación de agentes sociales, en busca de la ampliación de la autonomía local, dejando de lado el romanticismo de las infinitas asambleas y el apego al corporativismo. 


\section{BREVE ABORDAJE SOBRE PARTICIPACIÓN SOCIAL}

La participación social en el universo de 'Feria del Cerrado' (Feira do Cerrado) nos es distinta de lo que ocurre en la media brasileña puesto que es una construcción inherente a los agrupamientos de personas segundo sus contextos socio económicos.

En Brasil es notoria la ausencia de credibilidad en las políticas públicas, habiendo una enorme distancia entre gobernantes y gobernados. Eso es caracterizado por la indiferencia por parte de la población, que solo muy recientemente ha luchado por sus derechos. Por otra parte hay un acentuado paradojo de pasividad por parte de los distintos seguimientos que se quedan en la esperanza de que el gobierno sea responsable por todas las cosas.

Ese comportamiento de la populación ocurre por el hecho del poder público no conseguir gestionar de modo satisfactorio todo el territorio en el ámbito federal, regional y hasta local, disminuir el disparate de la distribución de rentas e implementar acciones duraderas para el bien de las comunidades. Además, concurre para el agravamiento de la situación, la ausencia de participación social que pueda propiciar el correcto aprovechamiento del capital social, que ha crecido y fortalecido a pasos lentos. Conforme Putnam (1994) apud Jacobi (2003, p. 318).

[...] las prácticas sociales que construyen ciudadanía representan la posibilidad de constituirse en un espacio privilegiado para cultivar la responsabilidad personal, la obligación mutua y la cooperación voluntaria. Las prácticas sociales que les sean inherentes se relacionan con la solidaridad en el encuentro entre derechos y deberes. La ampliación de la esfera pública ha colocado una demanda a la sociedad en términos de obtener una mayor influencia sobre el Estado, tanto con su limitación, asumiendo que la autonomía social supone trascender las asimetrías en la representación social, así como modificar las relaciones sociales en favor de una mayor auto organización social.

El tema de la participación inserido en debates internacionales ha sido recurrente en los discursos gubernamentales en diferentes esferas del poder, o por los liderazgos comunitarios y está "siendo propuesto dentro de patrones de universalización capaces de dar legitimidad a los actores sociales en ellos involucrados" (SAYAGO, 2007, p. 13).

En el concepto tradicional de la participación, "se moviliza la población para obtener ciertos recursos o para la consulta sobre ciertas decisiones y representaciones, con tanto que los lugares de dominación/dominados sean mantenidos" (FALEIROS, 1980, p. 76). Como se puede denotar, muchas veces la participación ha sido usada como instrumento de manipulación social, con el intuito de legitimar procesos que no siempre nascieron de la fuerza del lugar. En vista de todo eso es preciso desvendar los "procesos burocráticos de la participación, mostrando como el "uso de la participación" es construido y "vendido" por los tecnócratas de la globalización” (SAYAGO, 2007, p. 14).

Los argumentos presentados para conseguir la participación popular en las acciones sociales están, algunas veces, camuflados con aire de democracia, pero pueden esconder intereses espurios, por los tecnócratas de la globalización, o por ideologías político partidarias.

La participación popular se transforma en posibilidad de ampliación de acceso de los sectores populares en la perspectiva de desarrollo de la sociedad civil y de fortalecimiento de los mecanismos democráticos, así como 
para afianzar la ejecución de programa social en el contexto de las políticas de ajustes estructural y de liberalización de la economía y de la privatización del patrimonio del Estado, integrándose en el proceso de redefinición entre el público y el privado, dentro de la perspectiva de redistribuir el poder en favor de los sujetos sociales que en regla general no tiene acceso (JACOBI, 2003).

De lo expuesto se permite asegurar que es más difícil y lleva más tiempo a un individuo solo alterar ciertas situaciones adversas y construir un ambiente favorable para el suceso en determinada región. Entretanto, cuando se une con otros individuos, de forma organizada, con objetivos comunes, uniendo esfuerzos, podrá identificar las propias deficiencias y promover la solución de problemas, con base en la cooperación mutua y en la acción cooperativa. Esto es lo que sucede en el caso en estudio: las personas hoy asociadas a la 'Feria del Cerrado' (Feira do Cerrado) vienen procurando superar las adversidades con el objetivo de mantener simultáneamente la cultura y la renta von vista a la supervivencia.

Cunill Grau (1991) apud Jacobi (2003) definen dos campos interpretativos de la participación; de un lado, lo que se asocia con la democratización teniendo, como referencia el fortalecimiento de los espacios de socialización, de descentralización de poder y papel más autónomo de los sujetos sociales y de otro lado la participación a partir de la creación de instrumento de socialización de la política, reforzando su papel como medio, para realizar intereses y derechos sociales que demandan una actuación pública.

Para las participaciones sociales ocurrir debe haber primero, confianza, como una especie de amalgama presenteen las relaciones entre todos los participantes, en todos los niveles de representación directa e indirecta, para buena distribución de tareas y dividendos. Ser participante significa de algún modo ser solidario en las actividades del territorio, es tener la oportunidad de implementar una marca personal en el contexto colectivo, que en ello debe llevar la marca de todos.

\section{ACTIVIDADES ARTESANALES}

En Brasil, para muchas personas la producción de artesanía es la principal actividad productiva y de renta. Hay casos en que la artesanía sirve como la principal fuente de subsistencia para familias enteras y hasta para toda una comunidad.

Llevando como punto de partida esa premisa, Fernandes y Maia (2010) destacan que los primeros objetos artesanales fueron concebidos para que fuesen útiles, y no para que fuesen bellos. Eso parte del principio de que los primeros seres humanos ya producían artesanía, con la finalidad de ayudar en la sobrevivencia. En el siglo XI, la artesanía era desarrollada en oficinas por Mestres de oficios y aprendices. Ambos componían las corporaciones de oficio, siendo que allí no había división de trabajo y ellas propias eran responsables por el control de producción y por el comercio incipiente realizado en las ferias. El origen del mercado y de las ferias se dio alrededor del siglo XIII, dado que la comercialización ocurría en los feudos y era básicamente de cambios, pues la mayor parte de la producción estaba destinada al consumo propio, comercializándose solo el excedente. Hoy día, hay una situación bien distinta, una vez que se comercializa no solo las "sobras" o excedentes, tampoco se hacen cambios, pero se practica la venta de los productos hechos para ese fin. En los periodos posteriores al feudalismo, hubo una consolidación de ese comercio y mayor destaque a la producción artesanal. En el pre capitalismo, los artesanos recibieron el nombre de artífices y fueron los primeros asalariados manuales y trabajadores cualificados. 
La artesanía, además de servir para sustento de la familia de los artesanos, contribuye para la valoración cultural de determinada localidad. En ello es posible mostrar la cultura, la identidad, la simbología y la expresión de determinada etnia. "La actividad está ligada a los recursos naturales, al estilo de vida y al grado de comercio con las comunidades vecinas" (ALCALDE; LE BOURGELAT; CASTILHO, 2007, p. 224).

En la producción de la artesanía son indispensables la habilidad manual, la creatividad, el conocimiento de la cultura local y el gusto por la actividad. Es común decirse que en cada pieza de artesanía está impregnada el alma de la cultura del artesano. Cada pieza de artesanía cuando es llevada para otros lugares, lleva consigo el sentimiento de pertenencia de aquel que la ha producido.

Sobre el significado de la artesanía, Fernandes y Maia (2010) afirman que puede variar conforme el artesano, que detiene el savoir-faire (saber-hacer); el contexto social en que es producido, la cultura de determinado grupo y hasta aquel que se apropia del objeto.

En términos prácticos no basta producir las piezas de artesanía, es necesario que las ventas, en el sentido de que la cultura debe propiciar sobrevivencia, como en los demás casos. Por lo tanto, el artesano precisa conocer la materia-prima que será utilizada, componer el costo de un producto y saber cómo presentar y valorar su arte. Todavía, no debe extrañarse el hecho de que existen personas que atribuyen inmenso valor a las expresiones artísticas culturales, expreso en forma de artesanía y otras que no se valoran.

Una feria de artesanía, como es la 'Feria del Cerrado' (Feira do Cerrado) en la ciudad de Goiânia, también sirve como atractivo no solo para los moradores locales, pero también para los turistas, inclusive extranjeros, que se muestran deseosos de conocer un poco más sobre la cultura e identidad locales. Fernandes y Maia (2010, p. 62) relatan que "La permanencia de este tipo está ligada al fenómeno del consumismo y, más aún, a la diseminación del discurso que sus productos son 'auténticos', 'rústicos' y 'tradicionales'."

La 'Feria del Cerrado' (Feira do Cerrado) no se restringe a la artesanía, se presenta una serie de otros productos culturales, entre ellos, la comida típica del cerrado. Se saliente que la artesanía acá es comprendida como todo producto confeccionado de manera artesanal, de modo casero, sin utilización de grandes maquinas, cómo los utilizados en la industria.

Al contrario de los que muchos pensaran, la artesanía no es apenas estética y decorativa, pero puede tener finalidad como utensilio de su cotidiano. De toda manera la artesanía es tenida como recuerdo de cultura, del local visitado o de una persona querida. Tedesco (2006, p. 227) apud Fernandes; y Maia (2010, p. 63) avanzan, al afirmaren que artesanía es:

[...] al mínimo, correlacionar tiempos, culturas y contactos; es tener presente elementos que serán aprehendidos, acrecidos, intercambiados y enriquecidos con el contacto cotidiano inter y entre étnico, con herencias europeas, formas y trazos culturales producidos por la relación ambiental y social en el contexto del vivido, por las readaptaciones en razón de los cambios sociales, del ambiente y de los recursos y dominios tecnológicos presentes en temporalidades variadas.

Diferentes técnicas manuales de producción y materiales pueden ser utilizadas para obtenerse diversas formas de expresión de un producto artesanal. En muchos casos, más de una técnica y de materia prima pueden ser utilizadas en una misma pieza de artesanía. 
Sobre el aprendizaje de un trabajo manual, Alcalde; Le Bourgelat; Castilho (2007, p. 224) dicen que "es adquirida de manera práctica y formal, por medio de oficinas o de vivencia del individuo con el medio artesanal, en que el aprendiz maneja la materia-prima y las herramientas imitando los más entendidos en el oficio". Muchas veces el aprendizaje viene por tradición de la familia, los padres enseñan el modo de producción a sus hijos y nietos, pasando de generación a generación.

\section{FERIA DEL CERRADO, GIOÂNIA: LA PARTICIPACIÓN SOCIAL PARA EL DESARROLLO LOCAL}

En este trabajo, además de la investigación bibliográfica y documental, fue utilizada la técnica del estudio descriptivo, con entrevistas semi-estructuradas aplicada a los dirigentes y feriantes, bien como la observación de la feria y conversar con los feriantes con el intuito de conocerse la real situación, a fin de analizar cómo está siendo la relación entre los dirigentes y feriantes y verificar como se da la participación social.

La 'Feria del Cerrado' (Feira do Cerrado) está situada en la Avenida $\mathrm{H}$ esquina con la calle 72, en el barrio Jardín Goiás, municipio de Goiânia, Estado de Goiás, Brasil. Conforme su reglamento interno, la feria "es una iniciativa creada para viabilizar la exposición y comercialización de productos para la valorización de la cultura goiana y la preservación del bioma Cerrado" (FEIRA, s.d.).

En conformidad con la entrevista en el mes de mayo de 2013, la 'Feria del Cerrado' (Feira do Cerrado), comenzó en 04 de abril de 2004, con cerca de cuarenta quioscos de feriantes, a los Domingos, una vez por mes, cuando fue realizado un proyecto para el local. A partir del proyecto fue construida la infraestructura existente actualmente, como la denominada "Asa Delta" (en que parte de los quioscos se encuentran), el "coliseo" (área para presentaciones artísticas) y la Pasarela (local de circulación de los visitantes).

La 'Fundación Pro Cerrado' (Fundação Pró-Cerrado), se separó del proyecto, una vez que no era exactamente el foco de su trabajo. La Feria fue creada con la finalidad de mantener el 'Parque del Niño' (Parque da Criança), cuya manutención era sustentada por la 'Fundación Pro Cerrado' (Fundação Pró-Cerrado), con un costo en torno de cinco mil reales por mes, en la época. Las colaboradoras de la fundación, Alessandra Campos (responsable por el proyecto para capacitación de recursos), Kariaci (que ha dado la idea inicial de la Feria de artesanía) y Karina Benevides (que ha llevado los feriantes para la primera exposición) pensaran que si en aquel espacio hubiese una Feria de artesanía, sería una alternativa económica y cultural viable.

Al inicio, como la feria ocurría solo una vez al mes, el movimiento fue disminuyendo, pues el público se olvidaba de la existencia de la feria $\mathrm{y}$, con eso, los expositores no iban, ocurriendo una queda. En vista de eso fue creado el 'Consejo permanente de la Feria del Cerrado' (Conselho Permanente da Feira do Cerrado), compuesto por: Alessandra Campos, Lucas Faria (uno de los cantantes de la Feria), Larissa Mundi, Paulinho (responsable por crear toda la identidad de la Feria) y dos personas del 'Servicio Brasileño de Apoyo a las Micro y Pequeñas Empresas' (SEBRAE). (Serviço Brasileiro de Apoio às Micro e Pequenas Empresas) (SEBRAE). Después de dos meses de reunión, el día del artesano, 19 de marzo, consiguieron colocar 200 quioscos en la Feria, con la participación de un circo e realización de oficinas.

Los gobiernos del Estado y de los municipios no ayudaron financieramente la creación de esta Feria y de la infraestructura inicial. Recientemente el poder público pavimentó una parte donde queda el área de recreación.

Frente a la necesidad de administrar la Feria, dos años atrás, fue creada la 
'Asociación Cultural Feria del Cerrado' (Associação Cultural Feira do Cerrado), con aproximadamente treinta personas en su administración, compuesta por los propios feriantes. Pero, en muy poco tiempo ese número fue reducido a tres personas, en virtud de todo trabajo y tiempo que eran necesarios disponer para que la feria pudiese levantar nuevamente, pues estaba en decadencia. A partir de ese hecho realizaron una elección para algunas funciones, tales como presidente, tesorero, director artístico, entre otras, lo que resultó en la revaloración de sus objetivos, que son:

a) Contribuir con la revitalización del 'Parque del Niño' (Parque da Criança); Exponer y comercializar productos derivados de conceptos presentes en la cultura popular goiania;

b) Rescatar, preservar y promover la divulgación de la cultura de los pueblos del Cerrado;

c) Promover la educación ambiental e incentivar la preservación del medio ambiente;

d)Estimular la cualificación profesional y personal de sus expositores, por medio de asociaciones con el poder público, iniciativa privada y Organizaciones Sociales Civiles (OSC) nacionales o internacionales;

e) Ofrecer oportunidades de trabajo a nuevos artistas;

f) Proponer recreación saludable y educativo para toda familia goianienese;

g) Promover la iniciativa privada;

h) Representar los conceptos ya mencionados también en exposiciones y comercialización de productos y en eventos realizados fuera del 'Parque del niño' (Parque da Criança), en la ocasión de Ferias, Congresos y similares (FEIRA, s.d.).
Conforme el Reglamento Interno, para hacer parte de la Feria, los productos expuestos y/o comercializados deben tener como características: origen artesanal, afinidad con el arte y cultura popular y preocupación con la preservación ambiental y con los conceptos de sustentabilidad. Actualmente, una comisión evalúa los productos de los expositores, mediante análisis de una serie de ítem. El expositor interesado precisa obedecer al reglamento interno, bien como sus productos deben estar en consonancia conforme las características de la Feria.

Actualmente la "Feria del Cerrado" (Feira do Cerrado), es referencia para quien procura por artesanías en la ciudad de Goiânia. Últimamente, existe una lista para participar como expositor de la Feria, con más de 550 personas inscriptas. Para la mayoría de los feriantes, la 'Feria del Cerrado" (Feira do Cerrado), no es la única fuente de recurso y de exposición del trabajo. Muchos de ellos también participan de otras Ferias en la ciudad, pero se cree que esta Feria es un punto importante, principalmente para la divulgación de sus productos.

Con referencia a la participación social de los feriantes se verificó que todos están comprometidos con los ideales establecidos en el reglamento de la 'Feria del Cerrado" (Feira do Cerrado), no obstante, las muchas dificultades en se mantener la frecuencia en reuniones formales de la propia dirección. De otra parte, muchas de esas personas pertenecen a un nivel socio económico y formativo que las conducen a una postura de dejar las decisiones a cargo da la dirección electa por fuerza del Reglamento Interno. La mayoría de los expositores está satisfecha con la administración, a pesar de que siempre existen resalvos con algunas decisiones e investimentos que sean realizados. Entretanto, se sabe que es muy difícil obtener un consenso, además de que no todos que participan tienen la 
misma lectura y conocimiento de aquello que permea el desarrollo local, lo que es una de las características de la Feria, sin embargo no está escrito de forma explícita en el Reglamento Interno.

Segundo el relato obtenido en entrevistas con feriantes, antiguamente, el local era un área para deshacerse de cadáveres y punto de usuarios de drogas. Sin embargo, con la efectuación de la Feria, el lugar fue trasformado en un ambiente saludable de hogar, cultura, compra y participación social.

\section{CONSIDERACIONES FINALES}

En tiempo de aceleración de la globalización, de las innovaciones tecnológicas y de la velocidad delos medios de comunicación, se busca desvendar los desafíos para la calidad de vida, reuniendo un conjunto de esfuerzos para contribuir para el desarrollo local y sustentable de las diversas comunidades, por medio de herramientas de inducción para participación de los actores involucrados.

Es imprescindible que haya mejora en la calidad de vida en el ámbito social y cultural, propiciando mayor movilidad social, fundamental al procedimiento productivo local. En el caso específico, la necesidad de manutención y revitalización del 'Parque del Niño' (Parque da Criança). Fue la motivación que llevó a las personas a unirse y desafiar los problemas y dificultades a fin de propiciar una alternativa de auto sustento.

Al abordar la cuestión del desarrollo local, se percibe que la Feria involucra tanto el aspecto económico, como el aspecto social, espacial, cultural y étnico. Se ve que el factor económico es el más indicado por las familias que se benefician con la venta de sus productos. El factor social, por el ambiente que proporciona tanto a los feriantes como a los visitantes, por la interacción entre ellos, con la posibilidad de divertimiento y recreación. El Espacial, tiene su resultado en la expresiva mejora y revitalización del 'Parque del Niño' (Parque da Criança). Lo cultural ocurre por la muestra para el público en general, de la cultura goiana por medio de sus artesanías y presentaciones culturales y por fin el étnico, que demuestra la heterogeneidad y raíces de la población goianiense. Es cierto que la "Feria del Cerrado" (Feira do Cerrado) trae muchos beneficios para la población local, presenta la valorización de la cultura y del arte local, proporciona renta para las familias y proporciona chances de negocios futuros.

También la "Feria del Cerrado" (Feira do Cerrado) ofrece un atractivo para alimentación, recreación, cultura y distracción. En ese sentido, quedan posibilidades de profundar las investigaciones, a fin de exhibir todas las oportunidades que ella ofrece, sea en el ámbito social, económico, cultural y espacial.

\section{REFERÊNCIAS}

ALCALDE, E. de A.; LE BOURLEGAT, C. A.; CASTILHO, M. A. O papel dos agentes na comunidade de artesãos em Três Lagoas-MS, como instrumentos impulsionadores do desenvolvimento local. Interações - Revista Internacional de Desenvolvimento Local, Campo Grande, v. 8, n. 2, p. 223-4, set. 2007.

ALMEIDA, J. A.; BLOS, W. O marketing do turismo rural e o desenvolvimento sustentável. En: ALMEIDA, J. A.; FROEHLICH, M.; RIEDL, M. Turismo rural e desenvolvimento sustentável. Campinas: Papirus, 2000.

BENEVIDES, I. P. Para uma agenda de discussão do turismo como fator de desenvolvimento local. En: RODRIGUES, A. B. (Org.). Turismo e desenvolvimento local. 2. ed. São Paulo: Hucitec, 1999.

BRITO, A. M. de; CARON, A.; NASCIMENTO, D. E. do. Alternativas de desenvolvimento local Integrado e Sustentável. Cadernos temáticos, Brasília, n. 7, dez. 2005.

BUARQUE, S. C. Construindo o desenvolvimento local sustentável: metodologia de planejamento. 4. ed. Rio de Janeiro: Garamond, 2008. 
FALEIROS, V. P. A política social do estado capitalista: as funções da previdência e assistências sociais. São Paulo: Cortez, 1980.

FEIRA do Cerrado, [s.d.]. Disponible: <www. feiradocerrado.com.br $>$. Acceso en: 15 maio 2013.

FERNANDES, C. de A.; MAIA, C. E. S. Artesanato no e para o mercado: as redes de produção e comercialização dos artesanatos das Feiras Hippie e do Cerrado de Goiânia-GO. Caminhos de Geografia, Uberlândia, v. 11, n. 34, p. 62-74, jun. 2010.

FREGA, J. R.; LEMOS, I. S.; SOUZA, A. Relação dinâmica entre as estratégias competitivas e os sistemas de gestão de custos: um estudo de caso. In: CONGRESSO DA ANPAD, 31., Rio de Janeiro, 2007. Anais... Rio de Janeiro: ANPAD, 2007. (CD-ROM).

IRVING, M. de A. Participação - questão central na sustentabilidade de projetos de desenvolvimento. En: IRVING, M. de A.; AZEVEDO, J. Turismo: o desafio da sustentabilidade. São Paulo: Futura, 2002. p. 35-45.
JACOBI, P. R.: Espaços públicos e práticas participativas na gestão do meio ambiente no Brasil. Revista Sociedade e Estado, Brasília, v. 18, n. 1/2, p. 315-38, jan./ dez. 2003.

MORIN, E. Saberes globais e saberes locais - o olhar transdisciplinar. Rio de Janeiro: Garamond, 2010.

SAMPAIO, C. A. C. Planejamento para o desenvolvimento sustentável: um estudo de caso e comparativo de municípios. Florianópolis: Bernúncia, 2002.

SAYAGO, D. Os conselhos de desenvolvimento territorial: entre a participação e a representação. Revista Brasileira de Gestão e Desenvolvimento Regional, Taubaté, SP, v. 3, n. 4 (número especial), p. 9-21, nov. 2007.

SOUZA, M. J. L. de. Como pode o turismo contribuir para o desenvolvimento local? En: RODRIGUES, A. B. (Org.). Turismo e desenvolvimento local. 2. ed. São Paulo: Hucitec, 1999.

VILLARREAL, L. Z. Las paradoxas del desarrollo local y del turismo. México: Editorial Porrúa/ UAEM, 2012.

\section{Sobre los autores:}

Raquel Lage Tuma: Graduada em Turismo pela UCDB, Mestre em Turismo pela Universidade Ibero Americana e Doutorado sanduíche em Universidade de Paris IV Sorbone. Universidade Federal de Goiás. E-mail: tuma.raquel@gmail.com

Heitor Romero Marques: Licenciado em Ciências Naturais e Pedagogia, Especialista em Filosofia e História da Educação, Mestre em Educação - formação de professores. Doutor em Desarrollo Local em contexto territorial. Programa de Mestrado e Doutorado em Desenvolvimento Local - UCDB, MS. E-mail: heiroma@ucdb.br

Maria Elisabeth Alves Mesquita Soares: Geógrafa, Mestre e Doutora em Geografia pela Universidade Federal de Goiás. Professora Auxiliar nas Faculdades Alfredo Nasser e professora da Secretaria Estadual de Educação de Goiás. E-mail: geoelisabeth@gmail.com 